\title{
65. No Rapunzel in This Ivory Tower: Finding Your Collective and Overcoming Academic Isolation
}

\author{
Devon Cantwell ${ }^{1}$, Siobhan Kirkland ${ }^{2}$, Hannah Lebovits ${ }^{3}$, Maricruz \\ Osorio $^{4}$, Natalie Rojas ${ }^{5}$, Rosalie Rubio ${ }^{6}$, Sarah Shugars ${ }^{7}$, Rachel Torres ${ }^{8}$, \\ and Rachel Winter ${ }^{9}$
}

\author{
${ }^{1}$ University of Ottawa \\ ${ }^{2}$ Government of Canada \\ ${ }^{3}$ University of Texas-Arlington \\ ${ }^{4}$ Bentley University \\ ${ }^{5}$ University of California, Davis \\ ${ }^{6}$ George Washington University \\ ${ }^{7}$ New York University; Rutgers University \\ ${ }^{8}$ James Madison University \\ ${ }^{9}$ Eli and Edythe Broad Art Museum at Michigan State University; University of \\ California, Santa Barbara
}

In March 2019, a sub-group of the authors (referred to as the FIRE Collective throughout this piece) began to converse with one another via the Twitter private messaging function. Conversations were initially focused on experiences of gender-based inequity in academia and graduate school, but over time, discussions extended to other parts of our personal and professional lives. When the COVID-19 pandemic hit a year later, the group members were prepared to support one another through the unknown. We are writing this piece to provide an understanding of the layers of isolation within academia, particularly for graduate students, and to empower others to create intentional communities. Most notably, our group has been successful in dispelling feelings of isolation and supporting one another during the most difficult times, therefore substantially enhancing our graduate and professional education. In this piece, we discuss the structural issues that contribute to feelings of isolation within academia, our experience addressing isolation through establishing a collective, and we provide advice for how 
graduate students can form their own collectives. Finally, we discuss recommendations to the profession as a whole for addressing isolation.

At its core, "isolation" is a psychological state: the knowledge and feeling that—no matter how many people you physically see or communicate with—you are deeply, existentially, alone. Feelings of isolation can be evident in daily life, and can be core elements contributing to a number of mental health concerns (Hawkley and Cacioppo 2010). Feelings of isolation are common in academia across disciplinary boundaries(Bloch 2002; Hunter and Devine 2016), which is perhaps unsurprising in a profession where one's personal and professional identities are so closely intertwined, and where individuals are trained to be personally and professionally tied to their knowledge output. Overcoming professional isolation requires more than the raw tools of virtual communication, such as a social media account or even a regularly scheduled virtual forum. Combating isolation requires a rethinking and reorientation toward finding and securing deeply personal and professional connections and support systems.

Extending Anderson's approach to nationalism as reflecting an "imagined political community" of disparate individuals who consider themselves compatriots through their shared dedication to norms and institutions (Anderson 2006), one might first consider an academic's community as their discipline or some segment of their subfield. Yet, a core challenge to this notion is the fact that, contrary to popular belief, academics function as humans outside of their professional interests. While academics have a great need to connect with scholars whose substantive knowledge is similar to their own, we have perhaps an even greater need to connect with others whose lived experiences are similar. 
This is especially true of those whose personal identities are stigmatized within the academy. Women, gender minorities, people of color, first-generation college students, members of the LGBTQ2SIA+ community, disabled folks, and those with intersecting marginalized identities have unique experiences within academia and beyond. Yet none of these communities are monolithic, and there is no singular trait or experience that fully binds them together. This makes finding one's "community" in academia particularly challenging for scholars from marginalized groups. For these underrepresented populations, the colleagues who share the closest scholarly knowledge are unlikely to also share similar experiences of academic life.

\section{Gendered and Racial Dimensions of Isolation within Academia}

The most predominantly marginalized groups of scholars are women and people of color, and they face an industry that can be openly hostile to them, and discount their work. Academia's formal good-faith efforts to increase the number of our colleagues in these groups often fall short, even by our own standards (Devine et al. 2017). Women are more likely than men to leave higher education, and those who do manage to stay and continue to work are often promoted at lower rates (Brown and Samuels 2018; Key and Sumner 2019). The COVID-19 pandemic has only exacerbated demands on workload and caregiving, while also stripping away institutional support for women and other historically marginalized scholars within the discipline (Langin 2021). Recent work by BIPOC and women scholars illuminates the experiences of isolation and discounted labor in our discipline (O'Brien 2020). Specifically, the work of BIPOC scholars and scholarship that centers on the power dynamics of racial and ethnic discrimination continues to be underrepresented and marginalized in political science. This discounting is the artifact of 
many things that contribute to professional isolation, even in pre-pandemic times. To combat the intrinsic ostracism in academia, scholars turn to each other for support. Informal groups add space for vulnerability and growth, as well as physical and material assistance, which as Willoughby-Herard (2020) points out, is crucial to the success of scholars of color.

The FIRE Collective includes a number of women of color with different ideological leanings and research specializations. It also has members who are non-binary, queer, first-generation to college, and disabled, as well as several colleagues who are members of religious minority groups. In this group, we find strength in a diverse community that validates and encourages different experiences and insights. This community allows for open dialogue and discussion without the fear of "airing dirty laundry" when speaking frankly about our experiences with expectations in the academy. Graduate students who eschew or withdraw from support networks outside their programs are considered aspirational models for many programs. Subsequently, the strong implication is that upon entry into a graduate program, the identity of "graduate student" becomes the most paramount, prioritized over all others. Nonconformity in the form of family or care obligations, disability, financial limitations, and other circumstances put graduate students with multiple priorities at risk of being met with hostility and socio-professional sanctions from colleagues. Some in the FIRE Collective share concerns that we cannot speak freely about with academic colleagues; colleagues may conflate group memberships with our individual struggles, and sharing our difficulties can lead to poor judgments of our personal communities as a whole. As an informal group, we can discuss the personal and professional struggles of building successful careers without the pressure to 
perform respectability politics ${ }^{1}$ by wrapping authentic concerns into palatable packages to gain legitimacy and sympathy. Leading with a strong respect for boundaries, we can candidly discuss issues with departments, friends, families, and communities that arise from our differences from the norm. We also trust that the experiences and perspectives we share will not be unfamiliar and dismissed, actions that often generate and contribute to feelings of isolation. We can also trust that feedback and challenges to our ideas are coming from a place of care for one another, and a desire to see each member succeed. This allows for intellectual growth on a personal level, and communal growth for members of the FIRE Collective as we seek to earn respect from one another instead of from outsiders.

Professional advancement is built on the evaluation, validation, and acceptance of an author's ideas. These criteria also isolate academics who choose to focus on theories of politics that center on race and gender. At present, scholars of color and women who research these aspects of access to power are especially disregarded as niche, denigrated as "activist scholars," and siloed throughout the publication process. In a discipline that heavily prioritizes publishing, researchers who are under-cited, even within journals that publish more non-male authors, find few receptive homes for their research (Dion et al. 2018). Many of the rejections from these journals complain that research projects focused on race and gender are not relevant to the entire discipline, but the murders of George Floyd, Breonna Taylor, other countless racial injustices, and the subsequent protests across the world show that these projects are urgent matters across the discipline's major subfields. Given continuous self-selected disassociation from the

\footnotetext{
${ }^{1}$ Respectability politics in this context refers to the pressure to conform to mainstream and whitewashed standards of behavior and appearance which often serve to protect various systems of oppression in the academy. Examples of this in the academy may include things like not engaging in direct conflict, dressing extremely professionally, flat-ironing hair, and so on..
} 
scholarship that addresses these questions, the top journals have been unable to supply the discipline or the community at large with explanations and frameworks for comprehending the racial tensions of today. It is possible to support this work; Politics, Groups, and Identities has an entire syllabus ${ }^{2}$ of readings from their journal and continues to create micro-syllabi on the most urgent research questions. The FIRE Collective has offered a space to process and situate this work, and creates opportunities for intellectual exchange that is related to our own interests, personally or topically. We share and discuss resources like the PGI syllabus with each other, and collectively work to broaden perspectives in the field for ourselves, our peers, and our students.

Furthermore, any concerns that professional groups seek to exclude ignore the nature of mutual aid systems. Radically supportive networks provide intense, holistic, and constant support in the form of words of encouragement, peer review, and professional support, as well as direct aid for basic needs such as housing, food, and clothing when necessary. In order to provide this all-encompassing level of support-a level necessary because of the precarious, dismissive, and underfunded nature of graduate degree-seeking experiences — a group must spend significant amounts of time building trust. Intentionality and active participation are necessary for maintaining faith in the integrity of the foundation and sustaining the depth of the network. When groups get too large or members are too inactive, trust-building is far more difficult due to the diffuse and intermittent availability of support group members. Groups such as the FIRE Collective must focus on meeting the needs of its members and in doing so, maintain a higher threshold for member attentiveness. Members leverage their personal time, intellectual labor, and emotional effort to support one another on an on-call basis, which is practically difficult to do on

\footnotetext{
${ }^{2} \mathrm{https}$ //think.taylorandfrancis.com/pgi-black-lives-matter/
} 
a larger scale. While not intentionally exclusive, such personal investment in others requires a commitment to the cooperative space in the face of differing goals, personalities, and needs. Formed in response to the isolation graduate students from diverse social backgrounds experience in the academic space, the Collective provides radical and intense support beyond the conventional ideas of peer mentorship to directly address the ostracizing forces that hinder the professional advancement and success of its members.

\section{Community Building as Pedagogy in Graduate Education}

The patriarchal structures of graduate school and the larger social structures both isolate and disproportionately affect members of marginalized communities. This can make finding a community to help navigate feelings of isolation, discrimination, and exclusion difficult. Still, the ability to foster community with individuals with shared experiences and values is vital to an individual's success, and to the discipline at large.

There are limits to what a purely academic community can achieve since the academic system is built on structures that have long criticized, discriminated against, and experimented on marginalized groups. ${ }^{3}$ One way that marginalized scholars attempt to counteract this effect is through the formation of an extended support network. These networks are often initially formed in conference hotel lobbies or in brief coffee meetings with guest speakers. While these interactions are invaluable to development, in the midst of a pandemic and travel restrictions, marginalized scholars lose this contact as well.

\footnotetext{
${ }^{3}$ See chapters 56-63 for a more in-depth discussion of the challenges faced by different identity groups in political science.
} 
Social media can become a tool by which individuals find and create new communities. The vast nature of the internet allows for individuals to expand beyond the physical parameters of their departments and institutions to meet new people. In this way, one expands their network while also avoiding the conference fees that are often prohibitive. We provide junior members of the academy with professional information regarding conduct that is not officially taught within graduate programs but has real consequences for success. Colloquially termed as the "hidden curriculum" of graduate school, these skills are essential to master. The Twitter accounts of social scientists like Kim Yi Dionne, Jess Calarco, Raul Pacheco-Vega, Mirya Holman, and Emily Farris have devoted significant time to demystifying the hidden curriculum, while countless others ask questions, share insights, and generate discourse around the hidden curriculum daily. For graduate students with more limited means, discussions of the hidden curriculum on social media open up new pathways of access for first-generation, BIPOC, low-income, and Global South students. Moreover, personal relationships are not siloed from professional ones, as friends can be key readers for a new project, or create new connections with professional contacts. In this way, social media can act as a pivotal tool for diversifying political science networks. (For more information on the benefits (and challenges) of engaging on Twitter as a graduate student, see chapter 27. Additionally, Kim et al. (2021) provide a helpful guide for conceptually approaching networking.)

Graduate students often have limited access to information and perspectives on non-academic career paths and opportunities. As members of our collective have pursued different career paths after completing their graduate studies, including both academic and non-academic positions, we have helped provide the support that is often lacking in academia for 
those pursuing non-academic career paths, such as sharing job opportunities, interview advice, salary negotiation tips, revising resumes, and providing examples of cover letters. We have also remained connected even as we have pursued different career paths, and these connections have provided important perspectives on the relationship between academics and practitioners, highlighting the benefits of collaboration.

When our institutions and our disciplines cannot help us to overcome isolation, one can take to social media to create a new network. The difficulties of graduate school are only exacerbated when one cannot find their own Collective. Finding your group is important not only for handling the challenges of academia, but also remembering that outside of graduate school, you are also a person with emotional and social needs, and finding a means of personal and social fulfillment is imperative for success both within and beyond the discipline.

Creating communities online can be as simple as starting a group chat, a Slack channel, or setting weekly Zoom dates for chatting or coworking. What matters is that these methods of engagement are consistent, and encourage repeated interactions, going beyond one-off interactions in order to foster a true sense of community. For example, one member of our FIRE Collective has gone on to create several shared spaces online in an effort to build community with others facing similar isolation in their fields. She founded Jam3a, an online co-working space based on Slack that connects scholars and practitioners interested in the Middle East and North Africa. Similarly, she has applied this model to other groups to offer a platform that facilitates consistent interactions and community building.

\section{Transforming the Discipline}


Too often, efforts to build and nourish the types of communities capable of mitigating academic isolation are dismissed as distractions from the "real" academic work of research. It is not. It is absolutely essential to surviving and thriving in a discipline that is fundamentally designed for the archetype of a cisgender white man with no caregiving responsibilities. This archetype assumes that graduate students and faculty can spend unlimited amounts of time on teaching and research while discouraging boundaries on both time and labor. As such, institutions have implemented paltry support for caregivers as well as historically marginalized students and faculty. Additionally, many institutions continue to strip away the meager financial resources that exist. Collectives help fill in with support, advice, and even financial assistance where these institutions continue to fail.

Such supportive communities hold the power to change entire academic trajectories by reshaping who gets to stay in the academy, and who is forced out. It has the power to transform who gets to teach future generations. Building and participating in these spaces is a service to oneself and to the entire discipline. Our core recommendation then is that the discipline takes such service seriously. It is not an optional add-on, or a "nice to have"' feature of a scholar's profile.

For institutions and departments, this means valuing—during hiring and promotion decisions - the service scholars do in creating these spaces. It means supporting student attendance at conferences and actively teaching skills of lateral networking. It means building an expectation that members of your department will participate in external writing groups and support circles. 
For individuals, this means allowing yourself time and space to enjoy meeting new people. The best way to find "your people" is to meet as many people as possible. Value each one of them as a human being whose stories and perspectives enrich the world. Don't think of "networking" as a utilitarian expectation, but as an opportunity to make someone else feel valued and welcome. Remember: you are somebody else's people too.

In a scholarly sense, isolation may be inevitable. When you're working at the forefront of human knowledge, you are likely pushing forward the boundary of your tiny section alone. But you are not alone. There are people out there who can understand you, who can support you, who can help you come closer to being the kind of scholar you want to be. And you can help them too. Community, in a very real sense, is the antidote to isolation, and we owe it to ourselves and our discipline to build, value, and support the propagation of such remedies.

\section{References}

Anderson, Benedict R. O'G. 1991. Imagined Communities: Reflections on the Origin and Spread of Nationalism. Rev. and Extended ed. London; New York: Verso.

Bloch, Charlotte. 2002. "Managing the Emotions of Competition and Recognition in Academia." The Sociological Review 50 (2_suppl): 113-31. https://doi.org/10.1111/j.1467-954X.2002.tb03594.x.

Brown, Nadia E., and David Samuels. 2018. "Beyond the Gender Citation Gap: Comments on Dion, Sumner, and Mitchell." Political Analysis 26 (3): 328-30. https://doi.org/10.1017/pan.2018.14.

Devine, Kay, and Karen Hunter. 2016. "Doctoral Students' Emotional Exhaustion and Intentions to Leave Academia." International Journal of Doctoral Studies 11: 035-061. https://doi.org/10.28945/3396.

Devine, Patricia G., Patrick S. Forscher, William T.L. Cox, Anna Kaatz, Jennifer 
Sheridan, and Molly Carnes. 2017. "A Gender Bias Habit-Breaking Intervention Led to Increased Hiring of Female Faculty in STEMM Departments." Journal of Experimental Social Psychology 73 (November): 211-15. https://doi.org/10.1016/j.jesp.2017.07.002.

Dion, Michelle L., Jane Lawrence Sumner, and Sara McLaughlin Mitchell. 2018.

"Gendered Citation Patterns across Political Science and Social Science Methodology Fields." Political Analysis 26 (3): 312-27.

https://doi.org/10.1017/pan.2018.12.

Hawkley, Louise C., and John T. Cacioppo. 2010. "Loneliness Matters: A Theoretical and Empirical Review of Consequences and Mechanisms." Annals of Behavioral Medicine 40 (2): 218-27. https://doi.org/10.1007/s12160-010-9210-8.

Key, Ellen M., and Jane Lawrence Sumner. 2019. "You Research Like a Girl: Gendered Research Agendas and Their Implications." PS: Political Science \& Politics 52 (4): 663-68. https://doi.org/10.1017/S1049096519000945.

Kim, Seo-Young Silvia, Hannah Lebovits, and Sarah Shugars. 2021. "Networking 101 for Graduate Students: Building a Bigger Table.” PS: Political Science \& Politics, September, 1-6. https://doi.org/10.1017/S1049096521001025.

Langin, Katie. 2021. “'On the Verge of a Breakdown.' Report Highlights Women Academics' Pandemic Challenges.” Science, March 9, 2021. https://www.science.org/content/article/verge-breakdown-report-highlights-women-a cademics-pandemic-challenges.

O’Brien, Diana Z. 2020. "Navigating Political Science as a Woman." PS: Political Science \& Politics 53 (2): 315-17. https://doi.org/10.1017/S1049096519002154.

Willoughby-Herard, Tiffany. 2020. "Conferencing Is Not a Luxury and Neither Is the Scholarly Life of Our Future Colleagues." PS: Political Science \& Politics 53 (1): 146-48. https://doi.org/10.1017/S1049096519001082. 